\title{
Non-elastic matrix model for hydraulic networks calculation
}

\author{
V. E. M. G. Diniz ${ }^{1}$, P. A. Souza ${ }^{1} \&$ E. L. Junior ${ }^{2}$ \\ ${ }^{I}$ Department of Sanitary and Hydraulic Engineering of Polytechnic \\ School, São Paulo University, Brazil \\ ${ }^{2}$ Campinas State University, Brazil
}

\begin{abstract}
This paper presents a non-elastic matrix model to calculate hydraulic networks, based on a method created by Nahavandi and Catanzaro (Journal of Hydraulics Division, 99(HY1), pp.47-63, 1973). It is a method that calculates the discharges and pressure heads in hydraulic networks for the steady state, for the extended period and for the transient state. This method has advantages concerning the Cross method, because the latter does not allow the calculation of transient situations such as the settings of valves, the starting and stopping of boosters, the branch ruptures, etc. The applicability of the method created by Nahavandi and Catanzaro was enhanced, because the programming and input data to consider the presence of valves, reservoirs or boosters in the hydraulic network were developed. Furthermore, the mathematical formulation and programming to calculate the extended period and transient state were also developed. The matrix method is working well, because the model was applied to calculate some hydraulic networks used as examples and the values calculated by the model are similar to the ones obtained from the technical literature.
\end{abstract}

Keywords: hydraulic networks calculation and operation, software.

\section{Introduction}

In the water resources field, the unbalance between water supply and water demand obliges more and more elaborated solutions from the engineer. As countries develop, problems related to water, like cities supply, water transference among watersheds and mainly the lack and the difficulty to obtain 
financing founds to build new hydraulic works, demand the existing systems are more and more efficient.

The operational control of hydraulic networks to attend population demands during the day is a problem that has been searched for many years and until nowadays the solutions are not always optimized, resulting in flaw risks for water supply.

The operational control of hydraulic networks has many variables that must be controlled and optimized to obtain the best efficiency in operation, such as: a) water level in reservoirs; b) pressure heads all over the hydraulic network; c) number of valve settings; d) supply discharge; e) booster set ups; f) operations to avoid hydraulic transients.

The proposition of this paper is to develop a hydraulic network calculation model more efficient than the Cross method to calculate the pressure heads and discharges for the steady state and for the extended period and that can be applied to calculate slow transients without using the characteristic method.

\section{Literature review}

Ormsbee and Wood [2] proposed an algorithm that used a truncated expansion of Taylor's series to linearize the energy equations and the conservation of mass equations (written in terms of pipe diameter and velocity) for all network pipes and nodes respectively. This method is a modified version of the linear method apud Wood [9].

Jowitt and $\mathrm{Xu}$ [3] developed an algorithm to determine the values of flow control valve settings to minimize leakage. The non-linear basic hydraulic equations of the network, which describe the node heads and the flow rates in the pipes, are augmented by terms that explicitly account for pressure-depended leakage by terms that model the effect of valve actions. These equations were linearized using the method apud Wood [9].

Todini et al [4] apud http://www.dha.lnec.pt/nes/epanet/downloads /EN2Pmanual.pdf developed the "Gradient Method". This method solves the energy equations and the conservation of mass equations and the relation between discharge and head loss, which feature the conditions of hydraulic balance of the network in a given moment. The Gradient Method is used by computer programs as EPANET and WATERCAD.

Vairavamoorthy and Lumbers [5] developed an optimization method to minimize leakage in water distribution systems through the most effective settings of flow reduction valves. This problem was formulated as a nonlinear programming problem and solved using a reduced sequential quadratic programming method. The method showed advantages compared to previously published techniques in terms of robustness and computational efficiency. A feature of this approach is the use of an objective function that allows minor violations in the targeted pressure requirements. This allows a much greater improvement in the violations of minor pressure requirements that would be achieved otherwise. 
Filion and Karney [6] developed a hybrid model that combines the modeling sophistication of a transient simulator and the time-stepping efficiency of a quasi-steady state model and can simulate steady and unsteady interactions in a system over an extended period. The model's procedure consists of running water hammer simulations at the start and end of an extended time step to track the rate of filling of a system's reservoirs and then use this information to update reservoir levels at the end of the time step. Extended period and worst-case simulations presented in a case study suggest that the hybrid model has a high routing accuracy and can be used to identify the critical state, which will produce the most severe transients in a system.

Goulter [7] showed that the system analysis techniques, and in particular optimization, used to design water distribution networks have not been accepted into practice although the component design models are quite robust, versatile and capable of handling relatively complicated design problems. According to Goulter [7], it happens mainly because of the lack of suitable packaging of the models for ease of use in a design environment. There's also a lack of a network reliability measure due to the complexity of the reliability problem in water distribution networks. There is a need for development of decision support systems for design of water distribution networks. These systems should be able to combine optimization and simulation models and to use an interactive graphical basis to assist in the inclusion and interpretation of reliability in the network solutions and to develop alternative solutions.

Mpesha et al [8] used a frequency response method to determine the location and rate of leakage in open loop piping systems. A steady-oscillatory flow, produced by the periodic opening and closing of a valve is analyzed in the frequency domain by using the transfer matrix method, and a frequency response diagram at the valve is developed. Several piping systems were analyzed for all practical values of the friction factor (0.01-0.025) to detect and locate individual leaks of up to $0.5 \%$ of the mean discharge. The method, requiring the measurement of pressure and discharge fluctuations at only one location, has the potential to detect leaks in real life open loop piping systems conveying different kinds of fluids, such as water, petroleum and others.

\section{Method}

The non-elastic matrix model for hydraulic networks calculation is based on a method created by Nahavandi and Catanzaro [1]. It is a method that calculates the discharges and the pressure heads distribution in hydraulic networks for the steady state, for the extended period and for the transient state.

This method has great advantages concerning the Cross method, because the latter doesn't allow the calculation of transient situations such as the settings of valves, the starting and stopping of boosters, the branch ruptures, etc.

It will be adopted the following simplifying hypotheses: (1) incompressible fluid; (2) turbulent and isothermal flow; (3) non-elastic pipe; (4) it will be used the same friction factor "f" value to calculate the head loss in the transient state and in the steady state. 


\subsection{Mathematical formulation for the steady state}

A connection matrix [C], formed by the elements $1,-1$ and 0 is defined by the following way: each branch of the hydraulic network corresponds to a row in the matrix and each node of the hydraulic network corresponds to a column in the matrix. An element $\mathrm{Cij}$ of the connection matrix may have the following values:

$\mathrm{Cij}=0 \rightarrow$ If a branch $\mathrm{i}$ is not connected to a node $\mathrm{j}$.

$\mathrm{Cij}=-1 \rightarrow$ If a branch $\mathrm{i}$ is connected to a node $\mathrm{j}$ and the flow of branch $\mathrm{i}$ goes to a node $\mathrm{j}$.

$\mathrm{Cij}=1 \rightarrow$ If a branch $\mathrm{i}$ is connected to a node $\mathrm{j}$ and the flow of branch $\mathrm{i}$ comes from a node $\mathrm{j}$.

The method is based on 3 (three) equations written in matrix form. Eqn. (1) relates the pressure head difference on a branch to the pressure heads on the nodes at the beginning and at the end of the same branch.

$$
\left\{\frac{\Delta P}{\rho g}\right\}=[C]\left\{\frac{P}{\rho g}\right\}
$$

Eqn. (2) of the method is the continuity equation written to the nodes in matrix form:

$$
\left\lfloor C^{T}\right\rfloor\{Q\}+\left\{Q_{e s}\right\}=\{0\}
$$

Eqn. (3) of the method is the momentum equation written in finite differences form (matrix form):

$$
\begin{gathered}
\left\{\rho \frac{\pi D^{2}}{4} L\left(\frac{v-v^{0}}{\Delta t}\right)\right\}=\left\{\Delta P \frac{\pi D^{2}}{4}+\rho g \frac{\pi D^{2}}{4} L\left(\frac{\Delta Z}{L}\right)+\rho g H \frac{\pi D^{2}}{4}\right\}, \\
-\left\{\rho g \Delta H_{v} \frac{\pi D^{2}}{4}+F_{a v}\right\}
\end{gathered}
$$

After some algebraic operations in eqns. (3) an (2) and solving these equations to $\{Q\}$ and $\{P / r g\}$ respectively, the result is:

$$
\begin{gathered}
\{Q\}=\left\{Q^{0}\right\}+\left\{\beta \frac{\Delta P}{\rho g}+\beta \Delta Z+\beta H-\beta \Delta H_{v}-\beta P_{c}\right\} \\
\left\{\frac{P}{\rho g}\right\}=\left[M^{-1} \llbracket C^{T}\right]\left\{-\beta \Delta Z-\beta H+\beta \Delta H_{v}+\beta P_{c}-Q^{0}\right\}-\left[M^{-1}\right]\left\{Q_{e s}\right\}
\end{gathered}
$$

The numerical solution of the problem can be accomplished by solving eqns. (5), (1) and (4) using a computer. The input data to accomplish this analysis are: the hydraulic network topology, the geometric dimensions, the hydraulic properties, the initial conditions of the problem and the control variables.

Although the equations for the steady state consider the presence of boosters and valves, the software accomplishes the calculations considering only pipes, nodal demands and the presence or not of reservoirs with constant water levels. This procedure is adopted to give the user an idea of how the hydraulic network will work considering only the action of gravity acceleration. 


\subsection{Mathematical formulation for the extended period}

After the software finishes calculating the steady state, it begins to calculate the extended period during the day. The day is divided in 24 time steps of 1 hour each one to calculate the extended period and the user may decide the number of time steps to be calculated, varying from 1 to 24 time steps.

The extended period has the same equations of the steady state because any given time step corresponds to the steady state of that moment with its own features. The differences between the steady state and the extended period are that the user may decide if there will be boosters and/or valves operating during the day on the hydraulic network or not, if there will be the presence of reservoirs or not, the nodal demands may vary from a period to the next one and the reservoirs may vary the water levels. The reservoir water level variation is calculated by the continuity equation:

$$
\{\Delta H\}\{A\}=\Delta t\left\{Q_{e}\right\}-\Delta t\left\{Q_{s}\right\}
$$

To calculate the pressure heads on the hydraulic network nodes, $\{D H\}\{A\}$ is divided by $D t$ and the result is multiplied by $\left[M^{-1}\right]$ and added to eqn. (5):

$$
\begin{aligned}
\left\{\frac{P}{\rho g}\right\} & =\left[M^{-1}\right] \frac{\{\Delta H\}\{A\}}{\Delta t}+\left[M^{-1} \llbracket C^{T}\right]\left\{-\beta \Delta Z-\beta H+\beta \Delta H_{v}+\beta P_{c}-Q^{0}\right\}, \\
& -\left[M^{-1}\right]\left\{Q_{e s}\right\}
\end{aligned}
$$

After it, the numerical solution of the problem is reached solving eqns. (1) and (4).

\subsection{Mathematical formulation for the transient state}

After calculating the discharges and pressure heads to any given time step of the extended period, the coefficients $C_{e s}$ to the nodes that have nodal demands are calculated and then a diagonal matrix $\left[C_{e s}\right]$ is built having the $C_{e s}$ values in its diagonal. The following equation is used to it:

$$
\left\{\left(\frac{P}{\rho g}\right)^{0.5}\right\}\left[C_{e s}\right]=\left\{Q_{e s}\right\}
$$

In the transient state, the nodal demands values $\left(\left\{Q_{e s}\right\}^{*}\right)$ will be calculated using the hydraulic theory for discharge calculation through orifices and nozzles. The following equation is used:

$$
\left\{Q_{e s}\right\}^{*}=\left[C_{e s}\right]\left\{\left(\frac{P_{e s}}{\rho g}\right)^{0.5}\right\}
$$

The coefficients $C_{e s}$ values used in eqn. (9) are the same calculated at the end of the extended period time step because the variation of $C_{e s}$ values is small and the $C_{e s}$ values are also small. 
To calculate the pressure heads on the hydraulic network nodes in the transient state, it is used eqn. 10, developed from eqn. 5:

$$
\begin{aligned}
\left\{\frac{P}{\rho g}\right\}^{*}= & {\left[M^{-1}\right] \frac{\{\Delta H\}^{*}\{A\}}{\Delta t}+\left[M^{-1}\left[C^{T}\right]\left\{-\beta \Delta Z-\beta H^{*}+\beta \Delta H_{v}^{*}\right\},\right.} \\
& \left.\left.\left.+\left[M^{-1} \llbracket C^{T}\right]\left\{\beta P_{c}-Q^{0}\right\}-\left[M^{-1}\right] C_{e s}\right]\right\}\left(\frac{P_{e s}}{\rho g}\right)^{0.5}\right\}
\end{aligned}
$$

To calculate the pressure head differences on the hydraulic network branches in the transient state, the connection matrix [C] multiplies the pressure heads calculated in eqn. (10) using eqn. (11):

$$
\left\{\frac{\Delta P}{\rho g}\right\}^{*}=[C]\left\{\frac{P}{\rho g}\right\}^{*}
$$

To calculate the discharges in the hydraulic network branches in the transient state, the pressure head differences calculated in eqn. (11) are used in eqn. (12):

$$
\{Q\}^{*}=\left\{Q^{0}\right\}+\left\{\beta \frac{\Delta P^{*}}{\rho g}+\beta \Delta Z+\beta H^{*}-\beta \Delta H_{v}^{*}-\beta P_{c}\right\} .
$$

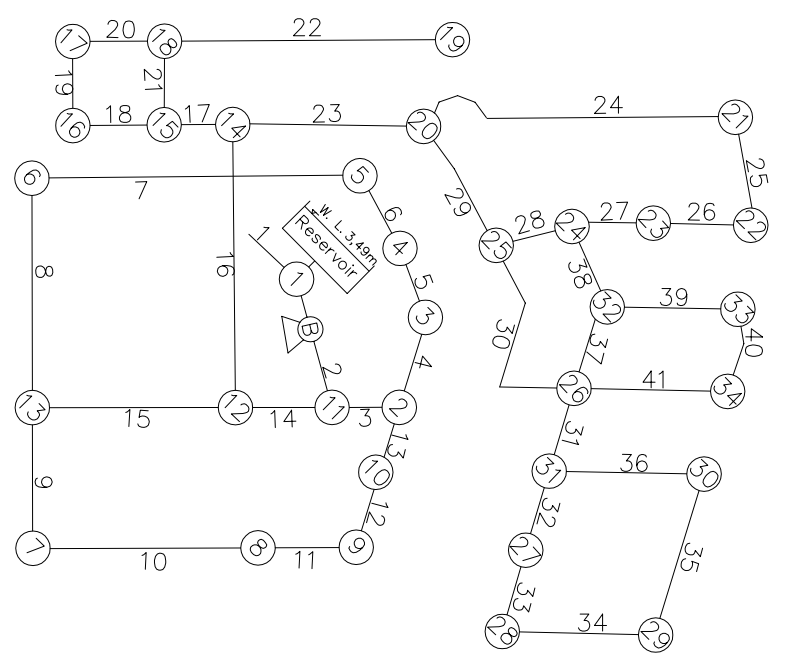

Figure 1: Hydraulic network scheme for the upper part of the neighbourhoods. 


\section{Results}

The non-elastic matrix model has already been tested to calculate many hydraulic networks. Two of these hydraulic networks are located at Paulínia - SP - Brazil. These hydraulic networks supply water to two neighbourhoods of Paulínia. One of them supplies the upper part of the neighbourhoods (fig. 1) and the other one supplies the lower part of the neighbourhoods. It was decided to use the hydraulic networks of Paulínia because the calculated pressure heads of some nodes of the hydraulic network were compared to the pressure heads gauged in situ on the same nodes of the hydraulic network.

Table 1: Input data for the hydraulic network of the upper part of the neighbourhoods for the steady state flow.

\begin{tabular}{|c|c|c|c|c|c|}
\hline node & $\begin{array}{c}\text { nodal demand } \\
(1 / \mathrm{s})\end{array}$ & $\begin{array}{l}\text { node elevation } \\
(\mathrm{m})\end{array}$ & pipe & $\begin{array}{l}\text { length } \\
(\mathrm{m})\end{array}$ & $\begin{array}{c}\text { diameter } \\
(\mathrm{m})\end{array}$ \\
\hline 1 & -4.77 & 640.20 & 1 & 0.10 & 0.200 \\
\hline 2 & 0.05 & 641.17 & 2 & 14.38 & 0.200 \\
\hline 3 & 0.05 & 640.60 & 3 & 32.55 & 0.200 \\
\hline 4 & 0.07 & 640.01 & 4 & 49.82 & 0.150 \\
\hline 5 & 0.23 & 636.47 & 5 & 59.29 & 0.100 \\
\hline 6 & 0.26 & 624.64 & 6 & 112.99 & 0.075 \\
\hline 7 & 0.22 & 627.28 & 7 & 426.13 & 0.050 \\
\hline 8 & 0.19 & 640.79 & 8 & 200.00 & 0.050 \\
\hline 9 & 0.04 & 641.37 & 9 & 100.00 & 0.050 \\
\hline 10 & 0.04 & 641.54 & 10 & 411.60 & 0.050 \\
\hline 11 & 0.05 & 641.06 & 11 & 48.28 & 0.075 \\
\hline 12 & 0.32 & 640.59 & 12 & 58.13 & 0.100 \\
\hline 13 & 0.30 & 625.96 & 13 & 46.72 & 0.150 \\
\hline 14 & 0.14 & 632.68 & 14 & 47.22 & 0.150 \\
\hline 15 & 0.12 & 632.50 & 15 & 411.60 & 0.050 \\
\hline 16 & 0.11 & 629.02 & 16 & 293.97 & 0.100 \\
\hline 17 & 0.11 & 626.39 & 17 & 27.06 & 0.075 \\
\hline 18 & 0.19 & 628.89 & 18 & 188.90 & 0.050 \\
\hline 19 & 0.08 & 624.55 & 19 & 66.13 & 0.050 \\
\hline 20 & 0.23 & 632.74 & 20 & 189.01 & 0.050 \\
\hline 21 & 0.20 & 623.61 & 21 & 65.38 & 0.050 \\
\hline 22 & 0.14 & 635.90 & 22 & 199.24 & 0.050 \\
\hline 23 & 0.09 & 639.48 & 23 & 19.00 & 0.100 \\
\hline 24 & 0.05 & 640.01 & 24 & 311.34 & 0.050 \\
\hline 25 & 0.18 & 640.04 & 25 & 164.29 & 0.050 \\
\hline 26 & 0.26 & 640.90 & 26 & 167.62 & 0.050 \\
\hline 27 & 0.06 & 640.15 & 27 & 36.39 & 0.075 \\
\hline 28 & 0.12 & 638.21 & 28 & 6.98 & 0.075 \\
\hline 29 & 0.14 & 635.06 & 29 & 218.31 & 0.100 \\
\hline 30 & 0.14 & 630.09 & 30 & 208.16 & 0.075 \\
\hline 31 & 0.14 & 640.89 & 31 & 66.70 & 0.075 \\
\hline 32 & 0.16 & 640.54 & 32 & 66.72 & 0.075 \\
\hline 33 & 0.13 & 630.58 & 33 & 66.39 & 0.050 \\
\hline \multirow[t]{8}{*}{34} & 0.14 & 623.98 & 34 & 209.78 & 0.050 \\
\hline & & & 35 & 132.74 & 0.050 \\
\hline & & & 36 & 209.93 & 0.050 \\
\hline & & & 37 & 135.95 & 0.075 \\
\hline & & & 38 & 69.47 & 0.075 \\
\hline & & & 39 & 179.63 & 0.050 \\
\hline & & & 40 & 131.72 & 0.050 \\
\hline & & & 41 & 209.85 & 0.050 \\
\hline
\end{tabular}


Although the comparison between the calculated pressure heads of some nodes and the pressure heads gauged in situ on the same nodes will be shown for both hydraulic networks, it was decided to show the results obtained for the steady state and for the extended period for the hydraulic network of the upper part of the neighbourhoods schemed in fig. 1 for being more complex than the other one.

It is necessary to say the hydraulic network results were calculated for 6 periods and that the absolute roughness of all pipes is $0.1 \mathrm{~mm}$ (PVC).

Table 2: Nodal demands to calculate the extended period for the hydraulic network of the upper part of the neighbourhoods.

\begin{tabular}{|c|c|c|c|c|c|c|}
\hline node & $\begin{array}{c}\text { period } 1 \\
(1 / s)\end{array}$ & $\begin{array}{c}\text { period } 2 \\
(1 / s)\end{array}$ & $\begin{array}{c}\text { period } 3 \\
(1 / s)\end{array}$ & $\begin{array}{c}\text { period } 4 \\
(1 / s)\end{array}$ & $\begin{array}{c}\text { period } 5 \\
(1 / s)\end{array}$ & $\begin{array}{c}\text { period } 6 \\
(1 / s)\end{array}$ \\
\hline 1 & -2.39 & -5.25 & -6.80 & -6.44 & -5.49 & -3.58 \\
\hline 2 & 0.03 & 0.06 & 0.08 & 0.07 & 0.06 & 0.04 \\
\hline 3 & 0.02 & 0.05 & 0.07 & 0.06 & 0.05 & 0.03 \\
\hline 4 & 0.04 & 0.08 & 0.10 & 0.10 & 0.08 & 0.05 \\
\hline 5 & 0.11 & 0.25 & 0.32 & 0.31 & 0.26 & 0.17 \\
\hline 6 & 0.13 & 0.29 & 0.38 & 0.36 & 0.30 & 0.20 \\
\hline 7 & 0.11 & 0.24 & 0.31 & 0.29 & 0.25 & 0.16 \\
\hline 8 & 0.10 & 0.21 & 0.28 & 0.26 & 0.22 & 0.15 \\
\hline 9 & 0.02 & 0.05 & 0.06 & 0.06 & 0.05 & 0.03 \\
\hline 10 & 0.02 & 0.05 & 0.06 & 0.06 & 0.05 & 0.03 \\
\hline 11 & 0.02 & 0.05 & 0.07 & 0.06 & 0.05 & 0.03 \\
\hline 12 & 0.16 & 0.35 & 0.45 & 0.43 & 0.36 & 0.24 \\
\hline 13 & 0.15 & 0.33 & 0.43 & 0.41 & 0.35 & 0.23 \\
\hline 14 & 0.07 & 0.16 & 0.20 & 0.19 & 0.16 & 0.11 \\
\hline 15 & 0.06 & 0.13 & 0.17 & 0.16 & 0.14 & 0.09 \\
\hline 16 & 0.05 & 0.12 & 0.15 & 0.15 & 0.12 & 0.08 \\
\hline 17 & 0.05 & 0.12 & 0.15 & 0.15 & 0.12 & 0.08 \\
\hline 18 & 0.10 & 0.21 & 0.27 & 0.26 & 0.22 & 0.14 \\
\hline 19 & 0.04 & 0.09 & 0.12 & 0.11 & 0.10 & 0.06 \\
\hline 20 & 0.12 & 0.25 & 0.33 & 0.31 & 0.27 & 0.17 \\
\hline 21 & 0.10 & 0.22 & 0.29 & 0.27 & 0.23 & 0.15 \\
\hline 22 & 0.07 & 0.15 & 0.20 & 0.19 & 0.16 & 0.10 \\
\hline 23 & 0.04 & 0.09 & 0.12 & 0.12 & 0.10 & 0.06 \\
\hline 24 & 0.02 & 0.05 & 0.07 & 0.06 & 0.05 & 0.04 \\
\hline 25 & 0.09 & 0.20 & 0.26 & 0.25 & 0.21 & 0.14 \\
\hline 26 & 0.13 & 0.29 & 0.37 & 0.35 & 0.30 & 0.20 \\
\hline 27 & 0.03 & 0.06 & 0.08 & 0.08 & 0.06 & 0.04 \\
\hline 28 & 0.06 & 0.13 & 0.17 & 0.16 & 0.13 & 0.09 \\
\hline 29 & 0.07 & 0.16 & 0.21 & 0.19 & 0.17 & 0.11 \\
\hline 30 & 0.07 & 0.16 & 0.21 & 0.20 & 0.17 & 0.11 \\
\hline 31 & 0.07 & 0.16 & 0.21 & 0.20 & 0.17 & 0.11 \\
\hline 32 & 0.08 & 0.18 & 0.23 & 0.22 & 0.19 & 0.12 \\
\hline 33 & 0.07 & 0.14 & 0.19 & 0.18 & 0.15 & 0.10 \\
\hline 34 & 0.07 & 0.16 & 0.21 & 0.19 & 0.17 & 0.11 \\
\hline
\end{tabular}

Ahead, it is shown in tables 4 and 5 the comparison between the calculated pressure heads of some nodes and the pressure heads gauged in situ on the same nodes of the hydraulic networks of the upper and of the lower part of the neighbourhoods respectively. Due to the hour of the day the pressure heads were gauged in situ, the calculated pressure heads correspond to the nodal demands used in period 3 of the extended period for both hydraulic networks. As already mentioned before, the input data and the results for the hydraulic network of the lower part of the neighbourhoods were not shown in this paper. 
Table 3: Obtained discharges for the hydraulic network of the upper part of the neighbourhoods.

\begin{tabular}{|c|c|c|c|c|c|c|c|}
\hline pipe & $\begin{array}{c}\text { discharge } \\
\text { steady state } \\
(1 / \mathrm{s})\end{array}$ & $\begin{array}{l}\text { discharge } \\
\text { period } 1 \\
(1 / s)\end{array}$ & $\begin{array}{l}\text { discharge } \\
\text { period } 2 \\
(1 / s)\end{array}$ & $\begin{array}{c}\text { discharge } \\
\text { period } 3 \\
(1 / \mathrm{s})\end{array}$ & $\begin{array}{l}\text { discharge } \\
\text { period } 4 \\
(1 / s)\end{array}$ & $\begin{array}{c}\text { discharge } \\
\text { period } 5 \\
(1 / s)\end{array}$ & $\begin{array}{c}\text { discharge } \\
\text { period } 6 \\
(1 / \mathrm{s})\end{array}$ \\
\hline 1 & -4.77 & -2.39 & -5.25 & -6.80 & -6.44 & -5.49 & -3.58 \\
\hline 2 & 4.77 & 2.39 & 5.25 & 6.80 & 6.44 & 5.49 & 3.58 \\
\hline 3 & 1.20 & 0.60 & 1.32 & 1.71 & 1.62 & 1.38 & 0.90 \\
\hline 4 & 0.60 & 0.30 & 0.66 & 0.85 & 0.80 & 0.69 & 0.45 \\
\hline 5 & 0.55 & 0.28 & 0.60 & 0.78 & 0.74 & 0.63 & 0.41 \\
\hline 6 & 0.48 & 0.24 & 0.52 & 0.68 & 0.64 & 0.55 & 0.36 \\
\hline 7 & 0.25 & 0.13 & 0.27 & 0.36 & 0.34 & 0.29 & 0.19 \\
\hline 8 & -0.01 & -0.01 & -0.02 & -0.02 & -0.02 & -0.02 & -0.01 \\
\hline 9 & -0.05 & -0.02 & -0.05 & -0.07 & -0.07 & -0.06 & -0.04 \\
\hline 10 & -0.26 & -0.13 & -0.29 & -0.38 & -0.36 & -0.30 & -0.20 \\
\hline 11 & -0.46 & -0.23 & -0.50 & -0.65 & -0.62 & -0.53 & -0.34 \\
\hline 12 & -0.50 & -0.25 & -0.55 & -0.72 & -0.68 & -0.58 & -0.38 \\
\hline 13 & -0.55 & -0.27 & -0.60 & -0.78 & -0.74 & -0.63 & -0.41 \\
\hline 14 & 3.53 & 1.76 & 3.88 & 5.03 & 4.76 & 4.06 & 2.65 \\
\hline 15 & 0.27 & 0.13 & 0.29 & 0.38 & 0.36 & 0.31 & 0.20 \\
\hline 16 & 2.95 & 1.47 & 3.24 & 4.20 & 3.98 & 3.39 & 2.21 \\
\hline 17 & 0.61 & 0.30 & 0.67 & 0.87 & 0.82 & 0.70 & 0.46 \\
\hline 18 & 0.17 & 0.10 & 0.19 & 0.25 & 0.24 & 0.20 & 0.13 \\
\hline 19 & 0.07 & 0.04 & 0.07 & 0.09 & 0.09 & 0.08 & 0.05 \\
\hline 20 & -0.04 & -0.01 & -0.05 & -0.06 & -0.05 & -0.05 & -0.03 \\
\hline 21 & -0.32 & -0.15 & -0.35 & -0.45 & -0.43 & -0.36 & -0.23 \\
\hline 22 & 0.08 & 0.04 & 0.09 & 0.12 & 0.11 & 0.10 & 0.06 \\
\hline 23 & 2.19 & 1.10 & 2.41 & 3.13 & 2.96 & 2.52 & 1.65 \\
\hline 24 & 0.24 & 0.12 & 0.26 & 0.34 & 0.32 & 0.27 & 0.17 \\
\hline 25 & 0.04 & 0.02 & 0.04 & 0.06 & 0.05 & 0.04 & 0.02 \\
\hline 26 & -0.10 & -0.05 & -0.11 & -0.14 & -0.14 & -0.12 & -0.09 \\
\hline 27 & -0.19 & -0.10 & -0.21 & -0.27 & -0.26 & -0.22 & -0.15 \\
\hline 28 & -0.98 & -0.49 & -1.07 & -1.39 & -1.32 & -1.13 & -0.74 \\
\hline 29 & -1.73 & -0.87 & -1.90 & -2.45 & -2.33 & -1.99 & -1.30 \\
\hline 30 & 0.57 & 0.28 & 0.62 & 0.80 & 0.76 & 0.65 & 0.43 \\
\hline 31 & 0.61 & 0.30 & 0.67 & 0.86 & 0.82 & 0.70 & 0.45 \\
\hline 32 & 0.28 & 0.14 & 0.31 & 0.40 & 0.38 & 0.33 & 0.22 \\
\hline 33 & 0.23 & 0.11 & 0.25 & 0.32 & 0.31 & 0.26 & 0.17 \\
\hline 34 & 0.11 & 0.05 & 0.12 & 0.16 & 0.15 & 0.13 & 0.09 \\
\hline 35 & -0.03 & -0.02 & -0.04 & -0.05 & -0.04 & -0.04 & -0.02 \\
\hline 36 & -0.18 & -0.09 & -0.20 & -0.25 & -0.24 & -0.20 & -0.13 \\
\hline 37 & -0.41 & -0.21 & -0.45 & -0.58 & -0.55 & -0.47 & -0.31 \\
\hline 38 & -0.74 & -0.37 & -0.81 & -1.06 & -1.00 & -0.85 & -0.55 \\
\hline 39 & 0.17 & 0.08 & 0.19 & 0.24 & 0.23 & 0.19 & 0.12 \\
\hline 40 & 0.04 & 0.02 & 0.04 & 0.05 & 0.05 & 0.04 & 0.02 \\
\hline 41 & -0.11 & -0.05 & -0.12 & -0.15 & -0.14 & -0.13 & -0.09 \\
\hline
\end{tabular}

Table 4: Comparison between the calculated pressure heads and the gauged pressure heads of the network of the upper part of the neighbourhoods.

\begin{tabular}{|c|c|c|c|c|c|}
\hline node & 7 & 16 & 28 & 29 & 31 \\
\hline $\begin{array}{c}\text { calculated pressure } \\
\text { heads }\left(\mathrm{mH}_{2} \mathrm{O}\right)\end{array}$ & 31.43 & 29.06 & 19.41 & 22.50 & 16.81 \\
\hline $\begin{array}{c}\text { gauged pressure } \\
\text { heads }\left(\mathrm{mH}_{2} \mathrm{O}\right)\end{array}$ & 30.00 & 29.00 & 18.00 & 20.00 & 16.00 \\
\hline
\end{tabular}


Table 5: Comparison between the calculated pressure heads and the gauged pressure heads of the network of the lower part of the neighbourhoods.

\begin{tabular}{|c|c|c|c|c|}
\hline node & 4 & 7 & 8 & 15 \\
\hline $\begin{array}{c}\text { calculated pressure } \\
\text { heads }\left(\mathrm{mH}_{2} \mathrm{O}\right)\end{array}$ & 28.64 & 48.00 & 31.97 & 42.25 \\
\hline $\begin{array}{c}\text { gauged pressure } \\
\text { heads }\left(\mathrm{mH}_{2} \mathrm{O}\right)\end{array}$ & 25.00 & 46.00 & 28.00 & 38.00 \\
\hline
\end{tabular}

\section{Conclusions}

The matrix method is working well, because the values calculated by the model for the hydraulic networks used as examples are similar to the ones obtained from the technical literature. The model was applied to calculate two real hydraulic networks. The calculated pressure heads of some nodes of the two hydraulic networks were compared to the pressure heads gauged in situ on the same nodes of the hydraulic networks and the results were close. The applicability of the method created by Nahavandi and Catanzaro [1] was enhanced, because the programming and the input data to consider the presence of valves, reservoirs or boosters in the hydraulic network were developed. Furthermore, the mathematical formulation and the programming to calculate the extended period and the transient state also were developed. The input data entry is easier, because in the method created by Nahavandi and Catanzaro [1] the user had to build himself the connection matrix and now the software itself builds the connection matrix. It was developed a technique to calculate the pressure heads on the nodes of the hydraulic networks (if being designed) in order to make the pressure heads stay below the maximum pressure head limit (input data) admitted by technical norms of the countries.

\section{Symbol list}

$\{D P / r g\} \quad$ pressure head differences on the branches $(\mathrm{m})$

$\{P / r g\} \quad$ pressure heads on the nodes $(\mathrm{m})$

$\left[C^{T}\right] \quad$ transposed matrix of the connection matrix

$\{Q\} \quad$ discharges of the branches $\left(\mathrm{m}^{3} / \mathrm{s}\right)$

$\left\{Q_{e s}\right\} \quad$ nodal demands $\left(\mathrm{m}^{3} / \mathrm{s}\right)$

$\{r\} \quad$ specific mass of the fluid $\left(\mathrm{kg} / \mathrm{m}^{3}\right)$

$\{D\} \quad$ branch diameter $(\mathrm{m})$

$\{L\} \quad$ branch length $(\mathrm{m})$

$\left\{v^{0}\right\} \quad$ present velocity $(\mathrm{m} / \mathrm{s})$

$\{v\} \quad$ future velocity (after $\Delta t)(\mathrm{m} / \mathrm{s})$

$\{D t\} \quad$ time gap calculated by Courant's condition (s)

$\{D P\} \quad$ pressure difference on the branch $(\mathrm{m})$

$\{g\} \quad$ gravity acceleration $\left(\mathrm{m} / \mathrm{s}^{2}\right)$

$\{D Z\} \quad$ elevation difference between the nodes that limit a branch (m)

$\{H\} \quad$ manometric head of an installed booster in a branch (m)

$\left\{D H_{v}\right\} \quad$ head loss of an installed valve in a branch (m) 


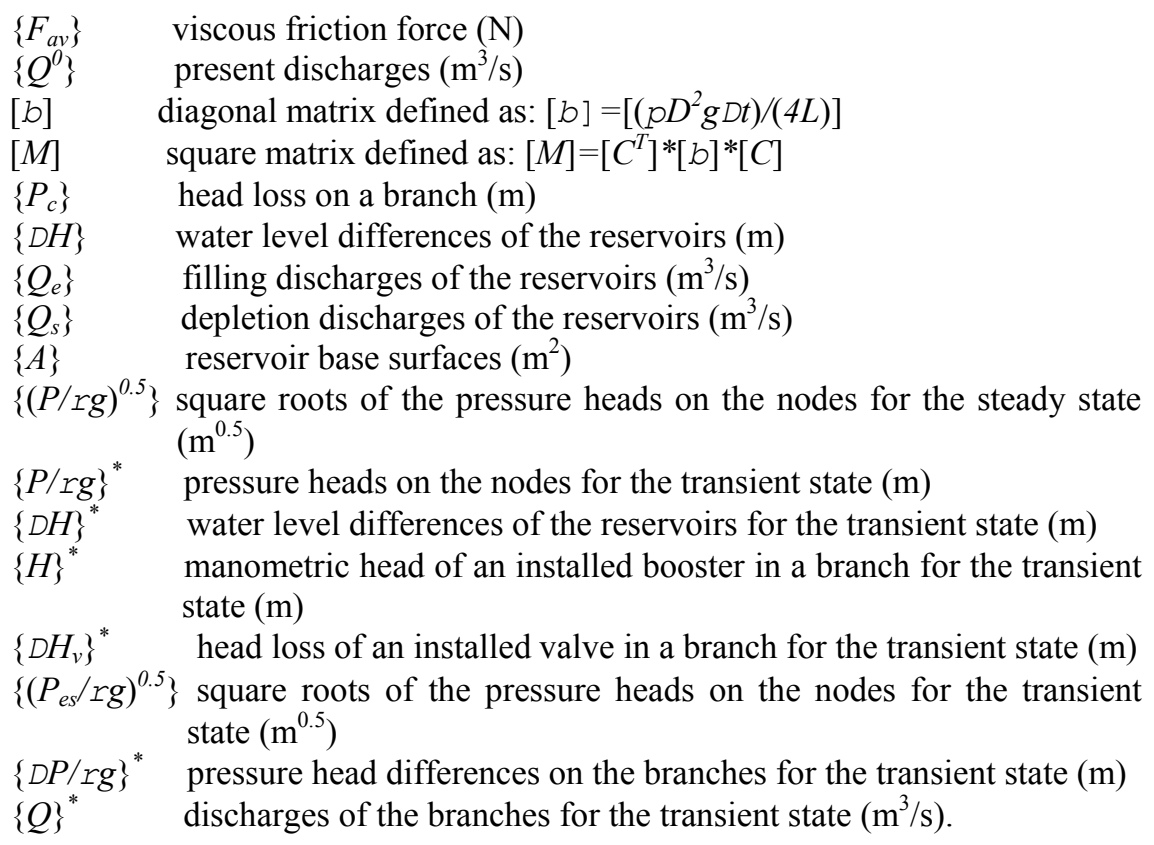

\section{References}

[1] Navahandi, A.N. \& Catanzaro, G.V., Matrix method for analysis of hydraulic networks. Journal of Hydraulics Division, 99(HY1), pp.47-63, 1973.

[2] Ormsbee, L.E. \& Wood, D.J., Hydraulic design algorithms for pipe networks. Journal of Hydraulic Engineering, 112(12), pp.1195-1207, 1986.

[3] Jowitt, P.W. \& Xu, C., Optimal valve control in water-distribution networks. Journal of Water Resources Planning and Management, 116(4), pp.455-472, 1990.

[4] User's handbook of EPANET 2 (PDF format) in Portuguese, http://www.dha.lnec.pt/nes/epanet/downloads/EN2Pmanual.pdf

[5] Vairavamoorthy, K. \& Lumbers, J., Leakage reduction in water distribution systems: optimal valve control. Journal of Hydraulic Engineering, 124(11), pp.1146-1154, 1998.

[6] Filion, Y.R. \& Karney, B.W., Extended-period analysis with a transient model. Journal of Hydraulic Engineering, 128(6), pp.616-624, 2002.

[7] Goulter, I.C., Systems analysis in water-distribution network design: from theory to practice. Journal of Water Resources Planning and Management, 118(3), pp.238-248, 1992.

[8] Mpesha, W., Gassman, S.L. \& Chaudhry, M.H., Leak detection in pipes by frequency response method. Journal of Hydraulic Engineering, 127(2), pp.134-147, 2001.

[9] Wood, Charles Journal of the Hydraulics Division, 98(HY7), pp. 1157-1170, 1972. 